\title{
P03-139
}

\section{SPIRITUAL BELIEFS AND THERAPEUTICALL ADHESION}

\section{Fonseca}

Psychiatry and Mental Health Department, Hospital S. Marcos, Braga, Portugal

Introduction: Personal and familiar spiritual and religious beliefs are important factors to be considered when prescribing an antipsychotic drug to a schizophrenic patient.

Description: A case report of a 29 years old male patient with a schizoaffective disorder is presented. In this case the border between what was delusion and what was the result of the patient personal and familiar spiritual beliefs was impossible to made. Only after the medication precribed has produced its effect this distinction has become clearer.

Method: A literature revision about this issue was made.

Discussion/conclusion: Spiritual beliefs are important factors that influence therapeuticall adhesion. A clear distinction between them and delusion symptomatology is very difficult to made, mainly in an acute psychotic state. After medication, the delusion symptomatology disappears and personal spiritual beliefs persist. 